\title{
MAX WEBER Y LA CONSTITUCIÓN DE IDENTIDADES: UN LEGADO PARA UN MUNDO DESENCANTADO
}

\section{Max Weber and the Constitution of Identities: A Legacy for a Disenchanted Word}

\author{
Eduardo Weisz* \\ Universidad de Buenos Aires (Argentina)
}

\section{Palabras clave \\ Max Weber Identidad Comunidad Irracionalidad Populismo}

\section{Keywords}

Max Weber Identity Community Irrationality Populism
RESUMEN: El artículo discute en primer lugar una definición del concepto de identidad para poder, a partir de esta, señalar el aporte específico que puede extraerse de la obra weberiana. Sin ser un término en el que este autor se haya detenido - su uso en las ciencias sociales es posterior-, su tratamiento de la constitución de comunidades, sobre todo religiosas y políticas, permite apreciar el interés del autor en los vínculos comunitarios. A partir de los procesos de identidad que Weber señala, por ejemplo en torno a etnias o a estamentos, puede apreciarse la importancia que le asigna a su carácter subjetivo, así como su énfasis en el aspecto irracional de estos vínculos. La perspectiva histórica weberiana resalta los lazos comunitarios constituidos en torno a las religiones y la incapacidad de la modernidad para reproducirlos. Sin embargo, puede encontrarse en Weber la aspiración a que en la política moderna pueda recuperarse algo de esa intensidad, por ejemplo en torno al problema nacional. Para finalizar, el artículo marca la potencialidad del populismo, un fenómeno de enorme extensión en la actualidad, para reproducir esos vínculos y dar a lo político una nueva entidad.

ABSTRACT: This article begins discussing a definition of the concept of identity, in order to be able to, departing from it, assess the specific contribution to it that can be read in Max Weber's work. Not being a concept in which Weber dwelt on much -in fact, it begun to be used in the social sciences much later-, his approach on the constitution of communities, specially of political and religious ones, shows the author's interest in the communal bonds. Looking at the identity processes he discusses, i.e. ethnical or status groups, the importance assigned to the subjective role in their constitution becomes apparent, as much as the irrational factors that allow for these social bonds. The historical prospective of Weber stresses the communal relationships established around world religions, and the incapability of Modernity to reproduce them in their intensity. Notwithstanding this, modern politics has for him the possibility of establishing communal bonds that may emulate the intensity those bonds used to have, for instance around the national problem. In the last section, the article points out to the potentiality of contemporary populism to allow the rise of new identities and, by this, to encourage new paths for politics.

\footnotetext{
* Correspondencia a / Correspondence to: Eduardo Weisz. Universidad de Buenos Aires, Departamento de Ciencias Sociales, Viamonte 430 (C1053 CABA, Argentina) - eduardoweisz@hotmail.com - http://orcid.org/0000-0003-4650-1532.

Cómo citar / How to cite: Weisz, Eduardo (2021). "Max Weber y la constitución de identidades: un legado para un mundo desencantado". Papeles del CEIC, vol. 2021/1, heredada 1, 1-10. (http://dx.doi.org/10.1387/pceic.21659).
}

Fecha de recepción: abril, 2020 / Fecha aceptación: agosto, 2020.

ISSN 1695-6494 / ㄷ 2021 UPV/EHU 


\section{HACIA UNA DEFINICIÓN WEBERIANA DE LA IDENTIDAD}

El concepto de identidad no ocupa un lugar específico en la obra weberiana; es, de hecho, incluso ajeno a su época. Sin embargo, sí atraviesa como problema diferentes fragmentos de su producción. Como parte del abordaje de diversos aspectos tratados por Max Weber - diseminados a lo largo de su obra - tiene una importancia decisiva en este autor, observable a partir de la relevancia que en su producción intelectual adquiere la constitución de comunidades religiosas o políticas. Aunque la conformación de identidades atraviese también otras esferas tratadas por Weber —la de las comunidades étnicas, por ejemplo-, las identidades mencionadas, religiosa y política, ocupan un lugar decisivo pues en ellas el autor encuentra una poderosa palanca histórica: la intervención de las grandes masas que puede coagular a partir de la constitución identitaria de las mismas.

Antes de penetrar el universo weberiano, es conveniente detenerse en el problema en sí, pues el concepto de identidad dista de ser unívoco y puede abordarse desde perspectivas muy diversas ${ }^{1}$. Resulta conveniente, por lo tanto, precisar y delimitar los aspectos que me interesan tratar aquí. En primer lugar, es necesario diferenciar la identidad individual de la colectiva. Ambas se solapan en la constitución de cada individuo, constituyen la entidad de cada cual. Mi mirada aquí se centrará en el componente específicamente colectivo de la identidad, conformado a partir de variables sociales y con incidencia en aspectos sociales del devenir histórico. Esta primera distinción, sin embargo, es sólo preliminar; es necesario, dada su vaguedad, mayor precisión en el concepto que buscaré desarrollar con referencia a las concepciones weberianas. Alfonso Pérez-Agote (2016) toma de John Turner los distintos niveles en los que se constituye la autoconcepción en un individuo ${ }^{2}$. Aquí me interesa detenerme en lo que Turner define como el segundo nivel, y que resume como compuesto por «las categorizaciones en términos de endogrupo/exogrupo, basadas en semejanzas y diferencias sociales entre seres humanos, que le definen a uno como miembro de determinados grupos y no de otros (por ejemplo "americano", "mujer", "negro", "estudiante", "clase trabajadora")» (apud Pérez-Agote, 2016: 3). Aunque acá está presente el núcleo conceptual que resulta relevante para el tratamiento de las identidades, es necesario, sin embargo, plantear un matiz que permite introducir el aporte de Weber al análisis de la constitución de identidades colectivas.

Los problemas ligados a la identidad aparecen en Weber centralmente a partir de dos tópicos conceptualmente cercanos al que aqui me ocupa: por un lado, la constitución de comunidades, $y$, por otro, la estratificación social a partir de estamentos. Aunque sin utilizar el significante identidad, en ambos casos Weber se plantea qué elementos permiten lo que hoy denominariamos constitución identitaria en un grupo social. Por otro lado, más allá de los análisis conceptuales, abstractos - típico-ideales-, en torno a lo que subyace a comunidades y estamentos - tal como los aborda en los textos que conocemos como Economía y sociedad (2014) - , es de gran interés el tratamiento por este autor de las identidades en los ámbitos religioso y político, esferas a las que asigna una relevancia histórica determinante.

1 Resulta ilustrativo, al respecto, que el seminario sobre identidad organizado por Claude Lévi-Strauss en el Collège de France en 1974/5 contó con exposiciones de disciplinas muy diversas: etnología, matemáticas, filosofía, biología, lingüistica y psicología.

2 John Charles Turner, psicólogo social británico, fue unos de los principales precursores de la teoría de la identidad social. Su uso en las ciencias sociales comienza en la década de 1960 y centralmente en el medio académico norteamericano. El concepto cobra auge, como puede observarse, con mucha posterioridad a los tiempos de Weber y como parte de un universo conceptual por completo ajeno a él. 
Desde este anclaje específico, más que una definición de características que conducen a la pertenencia a uno u otro grupo social a partir de sus semejanzas y diferencias con las de otro grupo, como surge del planteamiento de Turner, a Weber le preocupa cómo esas identidades logran constituirse, pudiendo así condicionar históricamente la acción social y la conducta de vida de quienes participan de esa identidad ${ }^{3}$. Pero esto, señala enfáticamente $-y$ lo repite en distintos pasajes-, ocurre solamente cuando esa semejanza "es sentida subjetivamente como una característica común» (1980: 234; 2014: 517). Es decir, y esto será lo que aquí se busca mostrar: la importancia social, e histórica, de las identidades se apoya centralmente en un sentimiento, más allá de las características objetivas que puedan compartir quienes tienen una identidad en común. Al referirse a los grupos étnicos, por ejemplo, Weber señalará que se crea una relación comunitaria - o, en lo que aquí interesa, una identidad colectiva - en la medida en que esos individuos «abrigan una creencia subjetiva en una procedencia común»; para la cual el "carácter étnico común (en el sentido que aquí se le da) no es en cambio en sí una comunidad (Gemeinschaft), sino que solo uno de los momentos que facilita el proceso de relación comunitaria (Vergemeinschaftung)" (1980: 237; 2014: 521] $)^{4}$. Las cualidades étnicas, objetivas, pueden fungir como condición para este tipo de Vergemeinschaftung, pero sin la creencia subjetiva - con o incluso sin fundamentos-, no hay comunidad.

Aquí Weber utiliza una expresión que tampoco ha sido fielmente vertida en la traducción al castellano, se refiere a la Zusammengehörigheitsglauben, la creencia en una pertenencia común. La versión de Fondo de Cultura Económica disuelve esto en la creencia en «una misma ascendencia "étnica"", quitándole el aspecto fundamental de que se cree en una pertenencia común, es decir, la concepción de que se es parte de algo en común, la que en Weber aparece reforzando el carácter subjetivo de algo que, en sí, no es más que una creencia (1980: $241 ; 2014: 525)$.

Como señalé, también en el análisis de los estamentos Weber destacaba lo que aquí me interesa resaltar en relación a la identidad. Pues para Weber, como nos recuerda Francisco Gil Villegas (2014) en una nota a su edición comentada de Economía y sociedad, mientras que las clases no implican necesariamente sentimiento de identidad ni la necesidad de participar en una acción colectiva de tipo político - «es pues una característica 'objetiva'»-, los estamentos siempre implican algún nivel de identidad basado en el prestigio y el honor. Por eso, agrega Gil Villegas: "[u]n estamento no puede existir sin que sus miembros tengan algún grado de conciencia con respecto a su pertenencia al mismo" (ibídem: 1115 y 1118). Por eso, señala Weber, «los estamentos son normalmente comunidades» (1980: 535; 2014: 1122), y es por esa conciencia de pertenencia, agrego, que estos se expresan «ante todo en la exigencia de un tipo específico de conducta de vida (Lebensführung) a todo aquel que quiera pertenecer a su círculo" (ibídem).

3 Llamo conducta de vida a lo que Weber denomina Lebensführung. Si bien conducción de vida sería una traducción más literal del término weberiano, considero que la idea de Weber, i.e. la forma en la cual se comportan los individuos en su vida, queda mejor expresada del modo aquí vertido.

4 A los fines de lo que me interesa destacar aqui, no quiero pasar por alto que el título del parágrafo del cual surge esta cita ha sido traducido al castellano por el Fondo de Cultura Económica como «Surgimiento de los caracteres raciales», mientras que el título original es "Entstehung ethnischen Gemeinsamkeitsglaubens. Sprach- und Kultgemeinschaft», que refiere al surgimiento de la creencia en que existe una etnia en común, y a la comunidad lingüística y de culto. Más allá de dejar de lado en la traducción la segunda parte del título, el original no habla de raza y, esto es acá lo central, refiere a una creencia (Glauben) en la pertenencia a una etnia en común. 
Dado este marco conceptual, podemos partir de la explicación de identidad ofrecida por Alfonso Pérez-Agote: "Una identidad colectiva lleva implícita, siempre, una definición social de una realidad colectiva. Esta definición no es real porque sea verdadera como tal definición. El componente cognitivo de un grupo es real independientemente de que sea verdadero desde un punto de vista científico. La definición es real porque existe, y existe mientras sigue siendo mantenida por los miembros y determinando su comportamiento" (2016: 6). Esta aproximación al concepto de identidad se complementa con la brindada por Josetxo Beriain, para quien la identidad es la "producción del 'nosotros' ideal, de la autoimagen colectiva que toda sociedad conlleva como un orden imaginado, como una representación cultural definida» (2000: 157).

Un aspecto central en el surgimiento de esta autoimagen colectiva y de los sentimientos que subyacen a una identidad colectiva, presente en la definición de Turner y también señalado por Weber, es «algún contraste respecto a quienes se constituyen notoriamente como otros» (1980: 234; 2014: 517), es decir, la identidad se constituye también a partir del sentimiento de pertenecer a un grupo y de sentirse diferente a quienes no pertenecen a este. Esta característica común a cualquier identidad tiene, como se verá, una gran importancia en las identidades religiosas y políticas.

\section{LAS IDENTIDADES EN LA CONSTRUCCIÓN HISTÓRICA DE WEBER}

En la perspectiva histórica de Weber, los procesos de conformación de identidad ocupan un lugar determinante. Las comunidades religiosas, al constituirse como tales, lo hicieron enfrentando y superando a la comunidad natural de linaje. Esta remitía a identidades colectivas fundadas y construidas «en torno al lugar de nacimiento, la lengua, la sangre, el estilo de vida. La fuerza de estos hechos 'dados' forja la idea que un individuo tiene de quién es y con quiénes está indisolublemente ligado" (Beriain, 2000: 157). En esos primeros lazos comunales las identidades surgían de esa pertenencia. Por ese motivo, las grandes religiones, en su intento por dar lugar a nuevas comunidades, tendieron a desarrollar en los creyentes una mayor cercanía con sus compañeros de fe que la que los unía a sus relaciones de sangre, de modo de poder romper con estas últimas. «Devaluando, al menos relativamente, tales relaciones y destruyendo la vinculación mágica y la exclusividad de los linajes, la profecía ha creado (...) una comunidad social nueva» (Weber, 1988: 542; 1998a: 533). Como explica Robert N. Bellah (2005), en lo que hace a su ética, las relaciones de linaje, más que ser rechazadas, se transforman y universalizan de modo tal de convertirse en el principio mismo de la religión. Esta fraternidad universal se apoya en el nuevo vínculo que surge entre los hermanos de fe. La religión, en definitiva, crea nuevos lazos entre los fieles de modo tal de dar lugar a una nueva identidad, análoga a la que se generaba en los linajes, pero ya no basados en la sangre sino en la fe, «incrementándose los preceptos que habían surgido de la ética de reciprocidad originada en la asociación de vecindad» hasta el «comunismo de amor fraterno» (Weber, 1988: 543; 1998a: 533).

Es en este contexto, el de las grandes religiones surgidas en torno al papel jugado por profetas, que Weber encuentra una de las expresiones de identidad más relevantes desde el punto de vista histórico. Refiere a esas religiones como un pneuma profético que atravesaba las congregaciones como un fuego tormentoso capaz de unir a los individuos con la fuerza de una soldadura (1985: 612; 1998b: 231). De ahí que, en comparación con aquellos, los lazos 
de identidad que pueden desarrollarse en la modernidad se nos presenten inevitablemente como devaluados. Este aspecto de nuestros tiempos es uno de los componentes que hacen al desencantamiento del mundo que Weber ve como destino fatal -inevitable y funesto- de la humanidad racionalizada. Por eso, a continuación de la descripción sobre el vínculo que unía a los individuos atravesados por las religiones proféticas, agrega Weber: «A quien no soporte virilmente este destino de nuestros tiempos», recomienda, "se le debe decir que mejor retorne en silencio (...) a los brazos, amplia y misericordiosamente abiertos, de las viejas iglesias» (1985: 612; 1998b: 232).

En el análisis de Weber, desarrollado principalmente en la Zwischenbetrachtung de sus ensayos sobre religión, una de las características distintivas que trae la modernidad es que corre el velo religioso que subsumía, hasta entonces, a todas las esferas en las que los individuos desarrollan su existencia. A partir de esta transición, cada una de esas esferas de vida pasa a seguir su propia lógica, sujeta a su dinámica específica (1988: 541-567; 1998a: 532-555). Entre estas esferas, en el marco de indagar sobre la concepción weberiana de la identidad, resulta de crucial importancia la política.

Si bien existen múltiples vínculos entre la esfera política y la religiosa que permiten entender por qué en la primera los lazos de identidad recuperan fuertes componentes de los que caracterizan a la religión (Weisz 2019b), es en torno a las luchas nacionales que este isomorfismo se hace más evidente.

Al tratar el problema de la nación, Weber utiliza un término muy similar al que, como señalé, emplea al referirse a las comunidades étnicas, y tampoco en este caso la traducción al castellano es fiel. La expresión en este apartado, primero aludiendo a lo étnico pero en seguida refiriéndose a la nación, es la de Zusammengehörigkeitsgefühl: el sentimiento de una pertenencia común (1980: 528-9; 2014: 1111]) . En este sentido, desde la perspectiva de identidad, la política puede erigirse como sucedáneo de la religión. Es posible que el zusammenschweissen -el unir por medio de una soldadura - no alcance en la política la contundencia de la identidad religiosa, impulsada por lo numinoso. Dios ha muerto, y es imposible que una esfera moderna logre subsumir todos los ámbitos en los que un individuo se despliega, que pueda unir y dar identidad en la medida en la que lo posibilitaba la religión. Pero la determinación nacional mantiene una gran capacidad de constituir identidades a partir del sentimiento de una pertenencia común. La nación es, para Weber, un sentimiento específico, y sus raíces deben buscarse en el sentimiento religioso.

Jose Santiago ha trabajado esta perspectiva siguiendo a Weber, y haciendo en consecuencia eje en «el sentimiento de solidaridad entre sus miembros que remite a un origen compartido (real o supuesto)" (2019: 144). Apoyándose en Anthony Smith, Santiago sostiene que religión y nación refuerzan «la frontera simbólica de la comunidad frente a quienes no forman parte de ella» (2019: 146). Como describe Beriain, en el paso de la religión a la política se produce "una transferencia de numinosidad de "lo absolutamente otro" (Dios) a la "alteridad generalizada" (la sociedad)», se substituye la presencia de seres sobrenaturales por una sacralización del constructo del "pueblo de una nación"» (2000: 161). De ese modo, apunta por su lado Pérez-Agote, "el nacionalismo, como vehículo de difusión de la idea y el sentimiento nacionales, restituirá progresivamente la cohesión emocional del grupo» (2016: 9).

5 La traducción de Fondo de Cultura Económica refiere a un "sentimiento de homogeneidad", perdiéndose asî nuevamente el aspecto crucial de pertenecer, de ser parte integrante, más que el poseer características iguales. 
En lo tratado hasta aquí se puede apreciar que, desde la perspectiva de Weber, la constitución de identidades se produce a partir de movilizar aspectos irracionales del individuo: los afectos, las emociones, las creencias no basadas en un abordaje racional. Antes de profundizar en otros aspectos de las identidades políticas, conviene detenerse en este aspecto. Pues en su estudio sobre el antiguo Israel, Weber enfatiza la fuerza política que la profecía religiosa despertaba en este pueblo, en contraposición con el carácter mucho más sobrio y racional de la política en la Grecia antigua (Weisz 2019a). Sin este diferencial brindado por las emociones, el judaísmo antiguo, caracterizado a la vez por su ruptura relativamente racional con la magia, no habría alcanzado su trascendencia histórica. En todo lo visto hasta aquí, el desarrollo de Weber al tratar comunidades étnicas o religiosas, estamentos o comunidades nacionales, está puesto en aspectos estrictamente irracionales. Lo mismo cabe señalar en el análisis de las identidades: su potencialidad histórica depende de esos aspectos irracionales ${ }^{6}$.

Max Weber debe ser leído en el contexto de su tiempo, una modernidad cuya consolidación apenas comenzaba a tomar forma en Alemania y tenía solo unas décadas en los países europeos más desarrollados. La lucha entre las potencias europeas fue un aspecto determinante a lo largo de su vida -incluyendo, en su última década, la Gran Guerra-, y los conflictos de clase alcanzaban su máximo desarrollo, bajo la forma que la revolución industrial venía de imprimirle a la época y que la revolución bolchevique creía consagrar. El llamado leninista a "explicar pacientemente" a las masas los mecanismos de explotación y la estructura de clases que estos generan, planteaba una concepción por la cual a la constitución de identidades de clase, a la conciencia de clase atribuida de Lukács $(1975)^{7}$, subyacía la aprehensión racional de la lógica del capital.

Al distinguir las clases de los estamentos, Weber atribuye la conformación de las primeras a la situación de mercado, a las posibilidades objetivas comunes dentro del mismo. Pero para este autor, como vimos, las clases no necesariamente constituyen comunidades, aunque puedan ser la base de las mismas (1980: 531; 2014: 1117]). Incluso, agrega, conceptualmente el concepto de uinterés de clase» es equívoco si se entiende algo diferente a la situación de mercado promedio de quienes pertenecen a la clase (1980: 532; 2014: 1118]): no constituye per se una "acción clasista», una comunidad ni, agregamos, genera identidad. Sin embargo, a la medida de una época que parecía poner al proletariado en el proscenio de la Historia, Weber veía en este sujeto la capacidad potencial de reconocer claramente el condicionamiento de la pertenencia a dicha clase, lo cual le permitiría un actuar en comunidad. Si bien no es algo que trate el propio autor, desde lo que aquí interesa cabe preguntarse si más allá del reconocimiento racional de la estructura económico-social existente, el movimiento obrero europeo de la primera mitad del siglo xx no desarrolló también lazos libidinales, de pertenencia, épicos e investidos de afectos producto de su actividad y compromiso con una organización sindical o partidaria. Es decir, hasta qué punto las grandes acciones de masas y la potente construcción de identidad de la clase obrera en aquellas décadas no tuvo también un importante componente irracional ${ }^{8}$. Sin referirse en particular a ese período de mayor exacerbación de la lucha

6 Weber, que dedicó buena parte de su actividad a la intelección del proceso histórico-universal de racionalización, alentaba lo irracional - valores, emociones-como modo de salvar un resto de libertad para el individuo y de vida política para una nación (Weisz, 2020).

7 Para Lukács: «la conciencia de clase es la reacción racionalmente adecuada que se atribuye de este modo a una determinada situación típica en el proceso de producción» (1975: 55).

8 Aunque exceda a lo que podemos desarrollar acá, la idea defendida por Ernesto Laclau (2008: 13-67) de un pueblo construido - también para analizar la revolución rusa como única forma de lograr una cierta totaliza- 
de clases en su sentido clásico, es lo que señalan Marcado Maldonado y Hernández Oliva en relación a los partidos políticos: «... para que los sujetos que se afilian a un partido político puedan compartir los principios ideológicos se requiere que los conozcan $y$, sobre todo, que coincidan con ellos, o por lo menos con la mayor parte de éstos; de tal manera que les sirvan como marcos de percepción y de interpretación de la realidad, y también como guías de sus comportamientos y prácticas. Pero esto no es observable, sólo lo pueden «sentir», experimentar, los sujetos mismos en las relaciones e interacciones que mantienen entre sí -al interior del partido-y con los miembros de otro partido político" (2010: 234).

En lo expuesto hasta aquí, se destaca el fuerte componente no racional que caracteriza para Weber a los lazos sociales de mayor trascendencia histórica. Esta matriz de pensamiento puede trasladarse al plano de la constitución de identidades, resultando el anclaje emocional imprescindible para cualquier identidad colectiva: las características objetivas comunes son insuficientes, por sí mismas, para conferir identidad colectiva a un grupo social. En lo que sigue, trataré de señalar la importancia del análisis weberiano esbozado para la comprensión de problemáticas contemporáneas pertenecientes a la esfera política.

\section{CLAVES WEBERIANAS SOBRE LA IDENTIDAD POLITIICA EN EL MUNDO CONTEMPORÁNEO}

Como sostiene Nancy Fraser (2017), el campo político contemporáneo carece de coherencia programática, de modo que reivindicaciones que durante décadas fueron constitutivas de identidades políticas masivas son reemplazadas por reivindicaciones sectoriales. "Con el descentramiento de la clase, diferentes movimientos sociales se han movilizado en torno a ejes transversales de diferencias» (ibídem: 27), dando lugar a reivindicaciones que se solapan y que esta autora resume como reivindicaciones basadas en la identidad, las que, siguiendo su análisis, da preminencia a la lucha por el reconocimiento. Fraser apunta a un aspecto determinante de la política contemporánea, la dificultad de que una única identidad albergue a una parte sustancial de la población. La identidad de género, por caso, se superpone con identidades surgidas en torno a bandas de rock o a equipos de fútbol. La identidad colectiva tiende a ser hoy una construcción de carácter inestable y lábil, lo cual no supone, naturalmente, decretar la desaparición de procesos radicados en identidades indisociables de la modernidad clásica, tales como la identidad de clase o nacional. Incluso, la identidad religiosa ha cobrado en las últimas décadas una importancia política decisiva en innumerables regiones del planeta, también en Occidente. Sin duda, como ha señalado Pérez-Agote en relación a la globalización en Europa occidental, «se ha roto el límite geográfico, social y político de la nación y el Estado" (2016: 10). Agentes supranacionales, sostiene, "toman decisiones que afectan directamente al individuo en aspectos centrales de su vida" (ibídem). En muchos aspectos, por lo tanto, la creencia en una pertenencia común, utilizando la expresión de Weber, atraviesa fronteras con gran facilidad. Como afirma Manuel Castells, «la multiculturalidad y la inmigración, dimensiones esenciales de la globalización, inducen el llamamiento a la comunidad identitaria» (2018: 35). Para Castells, esto deriva en que partidos e instituciones propios

ción compatible con una heterogeneidad irreductible- permite analizar las luchas del movimiento obrero en su momento más clásico desde una perspectiva no racionalista. 
de valores e intereses de otra época pierden legitimidad, lo que conduce a la búsqueda de nuevos actores políticos en quienes creer.

Con el breve recorrido realizado, quiero detenerme en esta última parte en plantear, a partir de Weber, algunas claves en torno a un tipo de identidad política de enorme relevancia en lo que va de este siglo, y directamente asociado a la búsqueda que postula Castells. No es necesario abundar en pruebas para afirmar que el populismo, los populismos, ha suscitado un interés descomunal, y justificado. Resulta de interés, en el marco de este artículo, que, en mucho mayor medida que los ideales republicanos, el populismo pone en juego aspectos claramente vinculados con la construcción de identidades. Su complejidad hace que cualquier definición sea controvertida, pero María Esperanza Casullo (2019), en un trabajo reciente sobre el populismo, remite a tres características distintivas. No son excluyentes, pero me permiten aquí acotar el problema. Dice Casullo que "se trata de fenómenos políticos en los cuales confluyen un líder con fuerte personalismo y centralidad política, que suscita el apoyo de un colectivo de individuos movilizados (...) detrás de un discurso antagonista que divide el campo político entre un "nosotros" popular y un "ellos" (la elite)" (ibídem: 40). Quiero referirme brevemente a estas tres características en base a lo que hemos tratado aquí.

La figura del líder remite indefectiblemente al análisis weberiano de la dominación carismática. Al trasponer la idea de carisma desde su origen religioso a su lugar político, Weber enfatizó el carácter emocional e irracional que conlleva el vínculo entre el caudillo y sus seguidores, así como el carácter afectivo del lazo comunitario que se establece entre sus prosélitos. Dicho lazo supone en realidad una identidad, tanto desde el lugar común a los seguidores que, por ejemplo, se perciben como víctimas del establishment o de la oligarquía, como, siguiendo en esto el clásico análisis de Freud (1972), una identidad ligada a una proyección en el líder de una figura paterna, común a todos los y las seguidoras del líder que, de ese modo, comparten una identidad análoga a la de linaje o a lo que el padre del psicoanálisis denomina la horda primitiva: "el individuo dotado de un poder extraordinario y dominando a una multitud de individuos iguales entre sí» (ibídem: 2596). Desde esta característica, y siguiendo a Weber en cuanto a la irracionalidad que constituye las identidades, el populismo se constituye en un claro motor de identidad.

El colectivo de individuos movilizados, el segundo aspecto destacado por la autora, no remite inmediatamente a una construcción de identidad. Sin embargo, en el marco de la heterogeneidad constitutiva de esta época - a diferencia de la modernidad clásica-, el populismo logra constituir un colectivo a través de una idea de comunidad que, como lo plantean Mudde y Rovira Kaltwasser, "retrata una identidad homogénea supuestamente auténtica e incorruptible» (2019: 51). Esta identidad, como señala Laclau9', se establece solamente a través de cadenas equivalenciales cambiantes, pues se trata de "una heterogeneidad que no puede ser subsumida bajo una única lógica "interna"» (2005: 186). Por ello, Laclau apela también al componente afectivo, irracional, que habilita a que se constituya el pueblo como colectivo, como identidad (ibídem). También en esta segunda cualidad, entonces, el populismo dinamiza construcciones de identidad, incluso a pesar de la heterogeneidad que caracteriza a esta etapa.

La tercera característica que señala Casullo, la división entre un «nosotros» y un «ellos», es, como se señaló supra, una cualidad que también caracteriza a las construcciones de identidad.

9 A los fines de este artículo resulta significativo que el célebre trabajo de Laclau sobre populismo (2005) se presenta como una investigación «sobre la lógica de formación de identidades colectivas» (ibídem: 9). 
En diversos análisis del populismo - Laclau (2005) o Mudde y Rovira Kaltwasser (2019), por dar dos ejemplos canónicos-, este es presentado como una construcción que "se sustenta en la distinción maniquea entre "el pueblo" (que es visto como una comunidad integra) y "la elite" (que es concebida como una entidad deshonesta e interesada solo en su beneficio propio)" (ibídem: 16). Por razones de espacio, no puedo extenderme en esto aquí (Weisz, 2019c), pero cabe señalar que subyace a esta división una de origen moral, específicamente religiosa, entre el «bien» y el «mal». Por eso, el «nosotros» y el "ellos» suele estar asentado en una división irracional, en la que la identidad se constituye en base a creencias, afectos, y odios.

En el artículo recién mencionado (Weisz, 2019c), se intenta mostrar como la perspectiva weberiana resultaba un aporte relevante para el análisis de los populismos. Uno de los aspectos que destacaba ahí es su rechazo para comprender la democracia republicana como un régimen racional basado en el gobierno del pueblo a través de sus representantes. Quienes, en cambio, sostienen esto, han atacado al populismo por su carácter irracional, por su apelación a las emociones, por la poca racionalidad que supone el seguimiento a un líder carismático. En ese artículo (ibídem), el legado weberiano me permitió enfatizar en qué medida la constitución de identidades se basa en lo no-racional, a la vez que mostrar, desde esta clave weberiana, como el populismo puede entenderse como una construcción de identidad que responde a la heterogeneidad de la sociedad contemporánea.

El abordaje weberiano de la constitución de identidades ilumina la comprensión del fenómeno populista, y algunas de las causas que lo han convertido en un fenómeno de enorme magnitud en la escena política contemporánea. Frente a un mundo desencantado, a democracias formales cuya legitimidad es crecientemente cuestionada, a la política como administración y cobertura legal de crecientes desigualdades, los populismos se erigen como alternativas. Sheldon Wolin definía a la política como aquello que permite que ciudadanos ordinarios creen democráticamente momentos de comunalidad (apud Weisz, 2019c: 214). Desde esta definición -indisociable de lo identitario que conlleva lo político-, y apoyándonos en Weber, cabe preguntarse si después de décadas en las que la política fue frecuentemente reemplazada por el New Public Management, por el There is no alternative thatcheriano, el populismo no es síntoma de una nueva politicidad y abre, como tal, nuevas perspectivas. El signo que estas tomen será, claro está, un terreno en disputa.

\section{BIBLIOGRAFÍA}

Bellah, R.N. (2005). Max Weber y el amor negador del mundo. Una mirada a la sociología histórica de la religión. En P. Aronson y E. Weisz (Comps.), Sociedad y religión (pp. 127-156). Buenos Aires: Prometeo.

Beriain, J. (2000). La lucha de los dioses en la modernidad. Barcelona: Anthropos.

Castells, M. (2018). Ruptura. La crisis de la democracia liberal. Madrid: Alianza.

Casullo, M.E. (2019). ¿Por qué funciona el populismo? Buenos Aires: Siglo XXI.

Fraser, N. (2017). ¿De la redistribución al reconocimiento? En J. Butler y N. Fraser (Eds.), ¿Reconocimiento o redistribución? Un debate entre marxismo y feminismo (pp. 23-66). Madrid: Traficantes de sueños. 
Freud, S. (1972). Psicología de las masas y análisis del yo. En Obras completas, Tomo VII (pp. 2563-2610). Madrid: Biblioteca Nueva.

Gil Villegas, F. (2014). Comentarios y anotaciones. En M. Weber, Economía y sociedad. Ciudad de México: Fondo de Cultura Económica.

Laclau, E. (2005). La razón populista. Buenos Aires: Fondo de Cultura económica.

Laclau, E. (2008). Debates y combates. Buenos Aires: Fondo de Cultura Económica.

Lúkács, G. (1975). Historia y conciencia de clase. Barcelona: Grijalbo.

Mercado Maldonado, A., y Hernández Oliva, A. (2010). El proceso de construcción de la identidad colectiva. Convergencia, 53, 229-251.

Mudde, C., y Rovira Altwasser, C. (2019). Populismo. Una breve introducción. Madrid: Alianza.

Pérez-Agote, A. (2016). La religión como identidad colectiva: las relaciones sociológicas entre religión e identidad. Papeles del CEIC, 2016/2(155), http://dx.doi.org/10.1387/ pceic. 16178

Santiago, J. (2019). Un nuevo «Dios» moderno. Nacionalismo y religión desde la sociología de Max Weber. En P. Lambruschini, J.I. Trovero y E. Weisz (Eds.), Viejos dioses, nuevos dioses. Política y religión a partir de Max Weber (pp. 139-154). Barcelona: Anthropos-Siglo XXI.

Weber, M. (1980). Wirtschaft und Gesellschaft. Tübingen: Mohr-Siebeck.

Weber, M. (1985). Wissenschaft als Beruf. En Gesammelte Aufsätze zur Wissenschaftslehre (pp. 524-555). Tübingen: Mohr-Siebeck.

Weber, M. (1988). Die Wirtschaftsethik der Weltreligionen. Zwischenbetrachtung: Theorie der Stufen und Richtungen religiöser Weltablehnung. En Gesammelte Aufsätze zur Religionssoziologie, I (pp. 536-573). Tübingen: Mohr-Siebeck.

Weber, M. (1998a). La ética económica de las religiones universales. Excurso. Teoría de los estadios y direcciones del rechazo religioso del mundo. En Ensayos sobre sociología de la religión, I (pp. 527-562). Madrid: Taurus.

Weber, M. (1998b). La ciencia como vocación. En El político y el científico (pp. 181-233). Madrid: Alianza.

Weber, M. (2014). Economía y sociedad. Ciudad de México: Fondo de Cultura Económica.

Weisz, E. (2019a). The Study on Ancient Israel and Its Relevance for Contemporary Politics. En E. Hanke, L. Scaff, y S. Whimster (Eds.), The Oxford Handbook of Max Weber (pp. 429441). Oxford: Oxford University Press.

Weisz, E. (2019b). Homologías entre política y religión. Una aproximación weberiana. En P. Lambruschini, J.I. Trovero y E. Weisz (Eds.), Viejos dioses, nuevos dioses (pp. 5-22). Barcelona: Anthropos-Siglo XXI.

Weisz, E. (2019c). Claves weberianas para un abordaje del populismo. En P. Lambruschini, J.I. Trovero y E. Weisz (Eds.), Viejos dioses, nuevos dioses (pp. 203-217). Barcelona: Anthropos-Siglo XXI.

Weisz, E. (2020). Science, Rationalization, and the Persistence of Enchantment. En Max Weber Studies, 20(1), 8-24. 